\title{
Meiotic segregation and interchromosomal effect in the sperm of a double translocation carrier: a case report Maria S Juchniuk de Vozzi ${ }^{1}$, Silvio A Santos ${ }^{1}$, Ciro S Pereira1, Juliana F Cuzzi 1,2, Lucimar AF Laureano ${ }^{1}$, José G Franco Jr ${ }^{3}$ and Lucia Martelli*1
}

Address: ${ }^{1}$ Department of Genetics, School of Medicine of Ribeirão Preto, University of São Paulo, Ribeirão Preto, SP, Brazil, ${ }^{2}$ Genesis Genetics Brasil, Rua Mato Grosso, 306 cjt 506, 01239-040, São Paulo, SP, Brazil and ${ }^{3}$ Center for Human Reproduction Prof Franco Junior, Av Prof João Fiusa, 689, 14025-310, Ribeirão Preto, SP, Brazil

Email: Maria S Juchniuk de Vozzi - juchniuk@rge.fmrp.usp.br; Silvio A Santos - sasantos@rge.fmrp.usp.br; Ciro S Pereira - cirosilveira@usp.br; Juliana F Cuzzi - jfcuzzi@yahoo.com; Lucimar AF Laureano - laflaureano@hotmail.com; José G Franco Jr - franco@crh.com.br;

Lucia Martelli* - lrmartel@fmrp.usp.br

* Corresponding author

Published: I December 2009

Molecular Cytogenetics 2009, 2:24 doi:10.1186/1755-8166-2-24
Received: I3 July 2009

Accepted: I December 2009

This article is available from: http://www.molecularcytogenetics.org/content/2/1/24

(c) 2009 Juchniuk de Vozzi et al; licensee BioMed Central Ltd.

This is an Open Access article distributed under the terms of the Creative Commons Attribution License (http://creativecommons.org/licenses/by/2.0), which permits unrestricted use, distribution, and reproduction in any medium, provided the original work is properly cited.

\begin{abstract}
Background: Infertility is a natural mechanism of selection intended to prevent the delivery of a child with malformations or mental retardation. Male infertility is closely related to chromosomal abnormalities. This study was focused on the analysis of meiotic segregation involving a Robertsonian translocation, $45, \mathrm{XY}, \operatorname{der}(13 ; \mid 3)[56] / 45, \mathrm{XY}, \operatorname{der}(13 ; \mid 4)[44]$ and the evaluation of possible interchromosomal effects.
\end{abstract}

Results: Hybridisation with LSI $|3 q| 4$ and subtelomere $14 q$ probes and WCPI3 SpectrumGreen and WCPI4 SpectrumOrange probes showed a high proportion of unbalanced gametes, corresponding to $71.2 \%$ of the spermatozoa. The disomic frequencies of the sexual chromosomes and chromosome 18 of the patient were higher $(5.28 \%$ and $2.55 \%$, respectively) than those of the control $(0.6 \%$ and $0.59 \%$, respectively).

Conclusion: Meiotic segregation studies in sperm are an important tool for genetic counselling of chromosomal aberrations, allowing for a prediction of the risks and consequent implications for the reproductive life. The patient with this rare translocation exhibited meiotic segregation fidelity, and a high rate of unbalanced gametes with disomic spermatozoa.

\section{Background}

Infertility is a natural selective mechanism that affects one in six couples [1] that is intended to prevent the delivery of a child with congenital anomalies or mental retardation. Pregnancy can be difficult to achieve when previous attempts have been associated with recurrent abortions or implantation failures. Several studies investigating the dif- ferent causes of infertility have included cytogenetic investigations to better understand the meiotic process [2-5]. Meiosis is a complex process and is monitored by different checkpoints, which are essential for proper cell division. Male and female gametes present different secondary responses to meiotic alterations. When an alteration occurs during spermatogenesis, meiosis halts, and 
apoptosis begins. On the other hand, if a problem occurs during oogenesis, meiosis continues to completion, thus generating aneuploid gametes. This fact could explain why the same chromosomal rearrangement causes male but not female infertility [6]. However, aneuploid gametes could still be generated during spermatogenesis if the meiotic checkpoints fail $[7,8]$.

Male infertility is closely related to somatic chromosomal abnormalities. Many studies have demonstrated that chromosomal aberrations that cause meiotic interruption can lead to oligozoospermia or azoospermia, which produce abnormal gametes and lead to infertility [9].

The genetic causes of male infertility include chromosomal (aneusomies, translocations, Y microdeletions, inversions), genetic, mitochondrial and genomic imprinting factors. The most common abnormalities are gonosomal aneuploidies and Robertsonian translocations [10]. Aneuploidies can be caused by meiotic segregation errors, non-disjunction due to recombination defects, paternal age effects and kinetochore and microtubule alterations. In contrast, structural abnormalities require DNA breakage as a prerequisite for the formation of rearrangements in other chromosomes. During meiotic recombination, DNA breakage can increase the susceptibility for the loss or gain of genetic material in a chromosomal region [11]. Patients with Robertsonian translocations can produce 3.4-40\% abnormal spermatozoa [12-16], while patients with reciprocal translocations have 47.5 - $81 \%$ abnormal germ cells [17-20].

Distinct combinations of Robertsonian translocations have been described for the five acrocentric chromosomes, with the 13;14 and 14;21 translocations being the most frequent. Although the Robertsonian translocation carrier is phenotypically normal, the abnormality contributes to genetic imbalances in the sibship, causing fetal losses, mental retardation, multiple congenital anomalies, uniparental disomy and infertility [21].

The first studies of meiotic segregation used heterologous in vitro fecundation $[22,23]$; later studies used fluorescent in situ hybridisation (FISH) techniques. The studies on meiotic segregation of chromosomes in the sperm of Robertsonian translocation males find a majority of normal or balanced spermatozoa for the chromosomes related to the translocation (mean 85.42\%; range 60-96.60\%) [24].

The influence of translocated chromosomes on the synapses and disjunction of other chromosomes is called an interchromosomal effect (ICE) [25]. ICE has been described in several chromosomal rearrangements. Chromosomal analysis of sperm in infertile males have shown high variability in chromosomal segregation behaviours during meiosis $[26,27]$. This variability could be associated with the multifactorial aetiology of male infertility, but in some cases, the combination of low sperm quality, chromosomal rearrangement and aneuploidies could affect meiotic synapses. It has been suggested that both the fluctuation in disomy and degree of semen parameter abnormalities are influenced by the chromosomes involved in the rearrangement. Different reports demonstrated an increased frequency of $\mathrm{X}$ and $\mathrm{Y}$ aneuploidies in patients with structural rearrangements involving autosomes [28,29,16,24]. Roux et al. (2005) [24] suggested that ICE could be detected in the sperm of Robertsonian translocation carriers, but this result could not be generalised.

This study analysed the meiotic segregation in a double Robertsonian translocation carrier with karyotype $45, \mathrm{XY}, \operatorname{der}(13 ; 13) / 45, \mathrm{XY}, \operatorname{der}(13 ; 14)$ and the possible interchromosomal effects in the sperm.

\section{Results}

A total of 1831 patient spermatozoa were included in the meiotic segregation analysis of the chromosomes involved in the translocation. A FISH analysis using WCP probes for the chromosomes 13 (red) and 14 (green) was performed in 820 gametes (figure 1). The 13 LSI probe (green) and subtelomere 14 (red) analysis were performed in 1101 sperm (figure 2). The results are summarised in Tables 1 and 2 . The hybridisation efficiency was $95 \%$ for LSI probes and 85\% for WCP probes.

We also investigated the interchromosomal effects through a segregation analysis of chromosomes $\mathrm{X}, \mathrm{Y}$ and 18 . We detected $49.32 \%$ of sperm with one red signal, corresponding to the $\mathrm{X}$ chromosome, and $45.28 \%$ of sperm with one signal from the Y chromosome. Two signals (one red and one green) were observed in $0.78 \%$ of the gametes. We also observed two red signals (XX) in $0.28 \%$, two green signals (YY) in $0.21 \%$ and disomy for chromosome 18 in $2.42 \%$ of the gametes.

The control analysis detected $49.1 \%$ of the gametes with one red signal $(\mathrm{X}), 49.3 \%$ with one green signal $(\mathrm{Y})$, $0.25 \%$ with $(\mathrm{XY}), 0.16 \%$ with $(\mathrm{XX})$ and $0.11 \%$ with (YY) disomic signals. The frequency of chromosome 18 disomy was $0.58 \%$ and diploidy was detected in $0.57 \%$ of cells.

\section{Discussion}

Meiotic segregation analysis can predict gamete behaviour in patients with chromosomal abnormalities and can be useful for genetic counselling purposes. This study provides accurate information for the understanding of meiotic segregation in male gametes in this particular Robertsonian translocation carrier. 


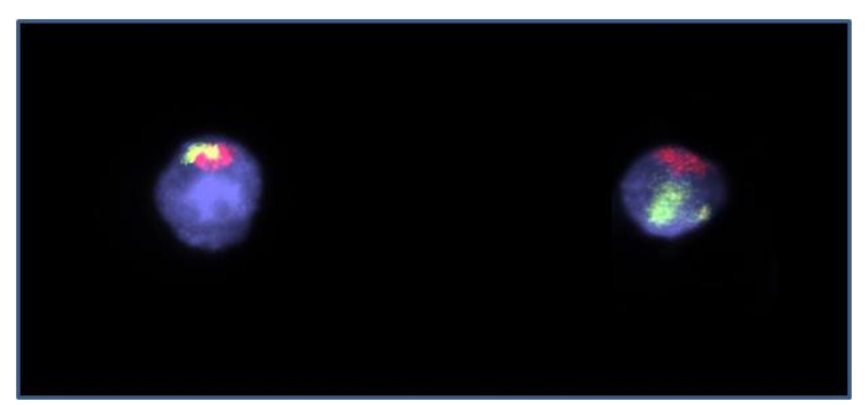

Figure I

A nucleus with the $13 ; 14$ translocation and normal sperm with one red signal (WCP I3) and one green signal (WCP |4).

In the literature, a rare type of mosaicism has been described. Jumping translocations are events in which the same chromosomal segment is translocated to different chromosome sites in different cell lines [30]. Jumping translocations have mainly been described in haematological malignancies, but there also have been rare observations of a constitutional condition. This could explain the origin of the patient mosaicism, considering that the parental karyotypes were normal. Iwarsson et al., 2009 described a phenotypically normal male who presented a 45,XY,rob(13;13)(q10;q10)/45,XY,dic(13;15) (p11.2; p12) karyotype and oligoasthenoteratozoospermia,

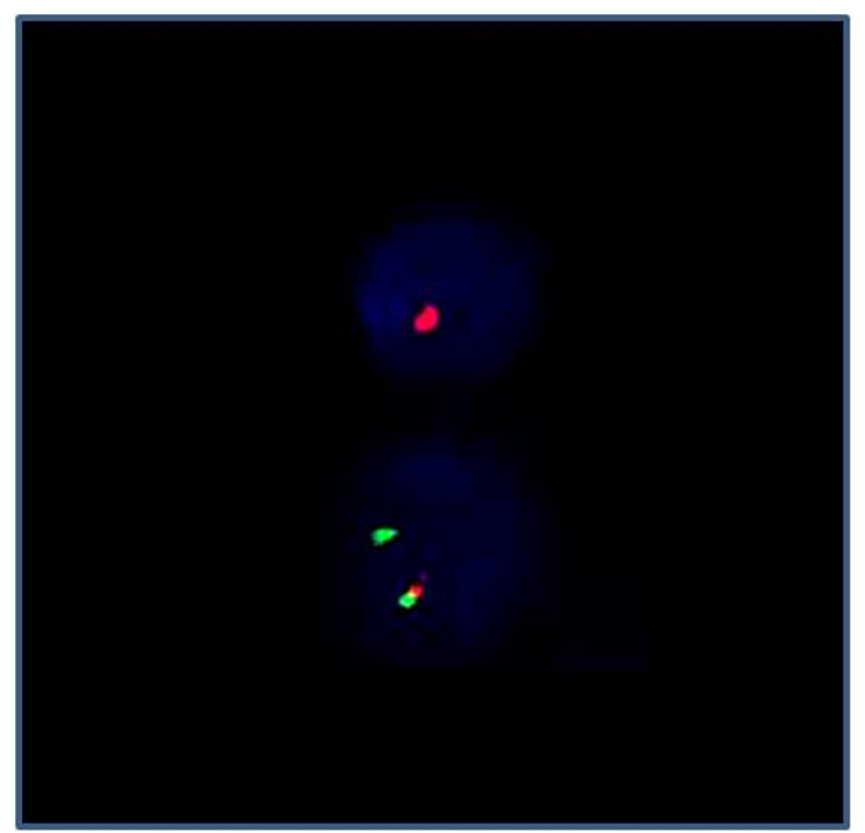

Figure 2

FISH in spermatozoa using LSI I 3 (green) and subtelomere I 4 (red) probes. One red signal and I 3 nulisomic; one red signal and disomic 13 nucleus. which is closely related to infertility. Another hypothesis for explaining this karyotype is chimerism, but further genetic informations would be necessary.

We compared the segregation modes of the patient sperm with the segregation described in non-mosaic Robertsonian translocations because there have been no reports in the literature concerning this particular type of meiotic segregation. Only one similar patient was published by Iwarsson et al. [31]. Most of the meiotic segregation studies in sperm with Robertsonian translocations have concluded that the alternate mode of segregation is more frequent $[29,24,4]$, indicating similar meiotic behaviour in different patients [13]. In our study, the balanced and normal gamete rates of alternate segregation were higher, in agreement with the literature $[29,24,4]$ for the $t(13 ; 14)$ cellular line. The chromosome complement $t(13 ; 13)$ (Figure 3) increased the rate of unbalanced gametes and increased the risk of trisomy 13 in the descendant because it does not produce balanced gametes. Meiotic interruption, which leads to 3:0 chromosomal segregation, could explain the observed rates in the sperm of the Robertsonian translocation carrier. Another explanation could be meiotic checkpoint intervention. Any factor able to modify anaphase (such as chromosomal rearrangement or the loss of microtubule tension) could interrupt the cell cycle [32].

In the meiotic segregation of the patient with $13 ; 13$ and $13 ; 15$ mosaicism, the rate of abnormal spermatozoa was $45.2 \%$, which is lower than our study $(72.22 \%)$. This could be explained by the genome of the involved chromosomes.

Comparing the meiotic segregation analysis in sperm and the frequency of abnormal embryos, Escudero et al. [13] concluded that meiotic segregation analysis are a good predictor for the rate of abnormal embryos. They concluded that there is a reasonable chance of conceiving when abnormal sperm rates are less than $65 \%$. Our results

Table I: The analysis of meiotic segregation of the patient using WCP probes.

\begin{tabular}{|c|c|c|c|}
\hline Chromosome constitution & Signals & $\mathbf{N}$ & Rate \\
\hline $13 / 14$ or $\operatorname{der}(13 ; 13)$ & OG & 307 & $37.43 \%$ \\
\hline $\operatorname{der}(13 ; \mid 4)$ & OUG & 248 & $30.21 \%$ \\
\hline $13 / \operatorname{der}(13 ; \mid 4)$ or $\operatorname{der}(13 ; \mid 3)$ & OOG & 26 & $3.17 \%$ \\
\hline 14 & G & 181 & $22.1 \%$ \\
\hline |4/der(|3;|4) & OGG & 36 & $4.4 \%$ \\
\hline \multirow[t]{2}{*}{13} & $\mathrm{O}$ & 22 & $27 \%$ \\
\hline & & 820 & $100 \%$ \\
\hline
\end{tabular}

$\mathrm{O}=$ orange; $\mathrm{G}=$ green; $\mathrm{OUG}=$ orange and green joined; $\mathrm{OOG}=$ two orange and one green; $O G G=$ two green and one orange; $O G=$ one orange and one green. 
Table 2: The analysis of meiotic segregation of the patient using LSI probes.

\begin{tabular}{|c|c|c|c|}
\hline Chromosome constitution & Signals & $\mathbf{N}$ & Rate \\
\hline $13 / 14$ or $\operatorname{der}(13 ; 14)$ & GO & 291 & $28.78 \%$ \\
\hline $13 / \operatorname{der}(13 ; 14)$ or $\operatorname{der}(13 ; 13) / 14$ & GGO & 265 & $26.21 \%$ \\
\hline 14 & $\mathrm{O}$ & 321 & $31.75 \%$ \\
\hline |4/der(13;|4) & GOO & 48 & $4.75 \%$ \\
\hline 13 & G & 47 & $4.65 \%$ \\
\hline \multirow[t]{2}{*}{ Others } & GG, O০, GGGO, GOO০ & 39 & $3.86 \%$ \\
\hline & & 1011 & $100 \%$ \\
\hline
\end{tabular}

$\mathrm{G}=$ green; $\mathrm{O}=$ orange.

have identified $71.22 \%$ abnormal gametes, including the alternate and adjacent modes of segregation. Consequently, our findings suggest a poor prognosis of conception, with an increased risk for fetal loss or trisomies in successful conceptions.

ICE remains controversial in the literature, although some publications have indicated its relevance [16]. Anton et al. [29] observed high sex chromosome aneuploidy rates $(0.68 \%)$ in the sperm of Robertsonian translocation carriers compared with controls $(0.37 \%)$ and insignificant rates for other chromosomes. In our study, we observed high levels of disomy for the sex chromosomes, in agreement with the literature $[33,28]$. Our results showed even higher rates than previously reported $[24,34]$. The checkpoints involved in meiosis could have failed, producing aneuploid gametes. Luciani et al. [35] described a nonrandom association between the trivalent and the sex chromosomes in prophase I in male mice. A similar study in mice with Robertsonian translocations also described an association between the trivalent and the sex chromosomes. Other groups described the association between the trivalent and sex chromosomes as the affinity between the inactive $\mathrm{XY}$ body and the asynaptic regions of the multivalent. This region is covered by the variant histone $\gamma$ $\mathrm{H} 2 \mathrm{AX}$, which increased this association and led to transcriptional inactivation [36,37]. The interference of the heterosynapses, the mechanism that rescues the gamete when anaphase is interrupted, could explain the increase of XY disomy. The interference of the trivalent in meiosis might affect the segregation of chromosome 18; its disomy frequency was increased when compared with the control $(\mathrm{p}<0.01)$. Another study also reported an increased frequency of chromosome 18 disomy [34]. Non-disjunction and the absence of recombination could also explain these rates [38].

When the meiotic segregation of a translocation is studied, the chromosomes involved in the translocation, as well as the genetic condition of each patient, must be considered. Meiosis is a very complex process; any change in the configuration and position of the chromosomes will increase the likelihood of meiotic arrest or errors.

\section{Conclusion}

We conclude that the study of meiotic segregation in the sperm of Robertsonian translocation carriers provides information about chromosomal imbalances and the increased risk of producing children with genetic syndromes. In our patient, we demonstrated accurate meiotic segregation, high rates of unbalanced gametes and disomic sexual germ cells in this rare translocation. Genetic counselling is required to explain the poor reproductive

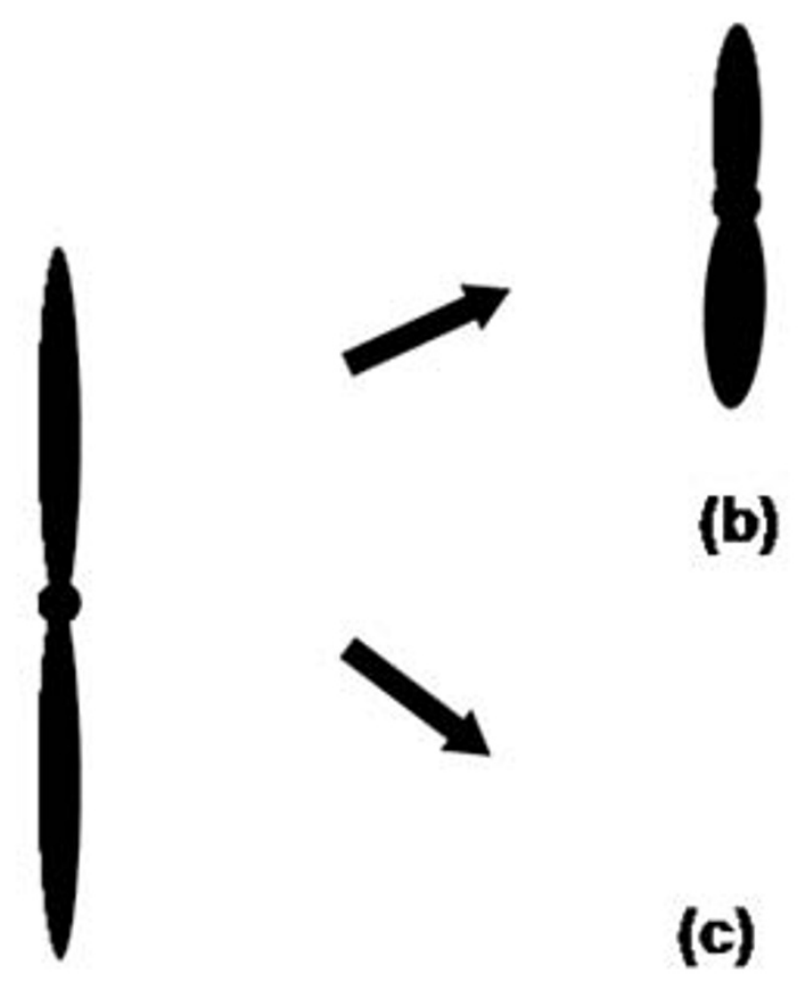

(a)

Figure 3

The meiotic segregation of translocation $t(13 ; 13)$. a) A derivative chromosome, b) a disomic gamete and c) a nullisomic gamete. 
outcome to the patient. The analysis of the segregation of chromosomes involved in the translocation and ICE can generate a more personalised risk assessment for the reproductive outcome of patients with structural chromosome aberrations that can be useful in genetic counselling.

\section{Methods}

Two sperm samples from a patient with the 45,XY, der(13;13)(q10;q10) [56]/45,XY,der $\quad(13 ; 14)$ (q10;q10) [44] karyotype were collected in sterile collectors. The phenotypically normal patient was 30 years old and presented oligozoospermia. At the same time, two sperm samples from a control (30 years old, fertile man without abnormalities, normal male karyotype and normal spermiogram) were also collected. The affected patient and the control were informed about the study, and written informed consent, approved by the Ethical committee, was obtained.

The samples were washed in $0.01 \mathrm{M}$ Tris/ $0.9 \% \mathrm{NaCl}$ solution. Slides were made with $5 \mu \mathrm{l}$ of the sample and stored at $-20^{\circ} \mathrm{C}$.

\section{FISH technique}

Two sets of probes, WCP (whole chromosome painting) for chromosome 13 (cat. $\mathrm{N}^{\circ}$ LPP13R, Cytocell, UK) and for chromosome 14 (cat $\mathrm{N}^{\circ}$ LPP14G, Cytocell, UK) and locus specific sequence (LSI) for chromosomes 13, LSI 13 (13q14) SpectrumGreen (cat $N^{\circ} 32-192018$, VYSIS Inc., USA) and TelVysion $14 \mathrm{q}$ SpectrumOrange (cat. $\mathrm{N}^{\circ} 33-$ 260014, VYSIS Inc., USA) were used for the meiotic segregation studies. CEP X (DXZ1), Y (DYZ1) sat III (cat N ${ }^{\circ} 30-$ 161050, VYSIS Inc., USA) and CEP 18 (D18Z1) SpectrumOrange (cat $\mathrm{N}^{\circ}$ 32-130018) and SpectrumGreen (cat $\mathrm{N}^{\circ} 32-132018$ ) probes (VYSIS Inc., USA) were used for the ICE analysis.

The samples were decondensed in $10 \mathrm{mM}$ DTT(dithiothreitol)/0.01 M Tris solution and LIS (lithium 3,5-diidosalicylate) solution at room temperature. They were dehydrated through an ethanol series and air-dried. Then they were immersed in $0.005 \%$ pepsin solution (Sigma, USA) for 10 minutes to eliminate the cytoplasm. The probes were prepared according to the manufacturer instructions. The slides were denatured in a water bath at $74^{\circ} \mathrm{C}$. The probe mix was then applied to the slides, which were covered with a coverslip, sealed with rubber cement and hybridised overnight in a moist chamber at $37^{\circ} \mathrm{C}$. The slides were washed in $50 \%$ formamide and $2 \times$ SSC solution, and DAPI (4',6-Diamino-2-phenylindole) was used for counterstaining. The results were analysed with an epifluorescence Zeiss microscope coupled with the Metasystem 2.1 software. Only morphologically intact sperm were assessed, according to standard assessment criteria.
Overlapping sperm nuclei, disrupted nuclei or large nuclei with diffuse signals were not considered [39]. In the painting assays, nuclei with two signals of different colours clearly coupled one with the other, were considered as displaying a balanced chromosomal pattern [40].

\section{Data analysis}

The statistical analysis was performed using the SAS system (2002-2003, SAS Institute Inc., Cary, NC) [41]. The data related to the analysis of the meiotic segregation of chromosomes $\mathrm{X}, \mathrm{Y}$ and 18 were analysed by the ChiSquare test $\left(\chi^{2}\right)$.

\section{Consent}

The affected patient and the control were informed about the study, and written informed consent, approved by the Ethical committee, was obtained.

\section{Competing interests}

The authors declare that they have no competing interests.

\section{Authors' contributions}

MSJV was responsible for the project, methodology, results and discussion. SAS and LAFL provided cytogenetic support. CSP and JFC provided FISH support and methodology. FJ provided the clinical information and LM was the advisor and coordinator. All of the authors read and approved the final manuscript.

\section{Acknowledgements}

We are grateful to the patient for his participation in this study. We would also like to acknowledge Luciana Veiga-Castelli for the text revision. This work was supported by CNPq, the National Research Council, DF, Brazil (scholarships to MSJV and CSP) and FAEPA HCRP-USP (grant funding to LM).

\section{References}

I. de Kretser DM: Male infertility. Lancet 1997, 349:787-790.

2. Martin $\mathrm{RH}$ : Cytogenetic analysis of sperm from a male heterozygous for a 13;14 Robertsonian translocation. Hum Genet 1988, 80:357-36।.

3. Shi Q, Martin RH: Aneuploidy in human spermatozoa: FISH analysis in men with constitutional chromosomal abnormalities and in infertile men. Reproduction 200I, I 2 I:655-66.

4. Chen $Y$, Huang J, Liu P, Qiao J: Analysis of meiotic segregation patterns and interchromosomal effects in sperm from six males with Robertsonian translocations. J Assist Reprod Genet 2007, 24(9):406-II.

5. Morel F, Douet-Guilbert N, Le Bris MJE, Le Herry A, Amice V, Amice J, DeBraekeleer M: Meiotic segregation of translocations during male gametogenesis. REVIEW. International journal of Andrology 2004, 27:200-2I2.

6. Paoloni-Giacobino A, Kern I, Rumpler Y, Djlelati R, Morris MA Dahoun SP: Familial t(6;2I)(p2I.I;pI3) translocation associated with male-only sterility. Clin Genet 2000, 58:324-328.

7. Hassold $T$, Hall $H$, Hunt $P$ : The origin of human aneuploidy: where we have been, where we are going. Review. Hum Mol Genet 2007, I 6(Spec No. 2):R203-8.

8. Hassold T, Hunt P: To err (meiotically) is human: the genesis of human aneuploidy. Review. Nat Rev Genet 200I, 2(4):280-9I.

9. Coco R: Trastornos genéticos en infertilidad masculina. Bol Inf SAA 200I, I0(3):64-7. 
10. Shi Q, Martin RH: Aneuploidy in human spermatozoa: FISH analysis in men with constitutional chromosomal abnormalities, and in infertile men. Reproduction 200I, I 21:655-666.

II. Baumgartner A, Van Hummelen P, Lowe XR, Adler ID, Wyrobek AJ: Numerical and Structural Chromosomal Abnormalities Detected in Human Sperm With a Combination of Multicolor FISH Assays. Environmental and Molecular Mutagenesis 1999, 33:49-58.

12. Rousseaux S, Chevret E, Monteil M, Cozzi J, Pelletier R, Delafontaine $D$, Sele B: Sperm nuclei analysis of a Robertsonian $\mathbf{t}(\mathbf{I} \mathbf{4} \mathbf{2} \mathbf{I} \mathbf{q})$ carrier, by FISH, using three plasmids and two YAC probes. Hum Genet 1995, 96:655-660.

13. Escudero T, Lee M, Carrel D, Blanco J, Munne S: Analysis of chromosome abnormalities in sperm and embryos from two 45,XY,t(13;| 4)(q |0;q |0) carriers. Prenat Diagn 2000, 20(7):599-602.

14. Honda H, Miharu N, Samura O, He H, Ohama K: Meiotic segregation analysis of a 14;2I Robertsonian translocation carrier by fluorescence in situ hybridization. Hum Genet 2000, 106:188-193.

15. Frydman N, Romana S, Le Lorc'h M, Vekemans M, Frydman R, Tachdjian G: Assisting reproduction of infertile men carrying a Robertsonian translocation. Hum Reprod 200I, 16:2274-2277.

16. Morel F, Roux C, Bresson JL: FISH analysis of the chromosomal status of spermatozoa from three men with 45,XY,der(13;I4)(qI0;qI0) karyotype. Mol Hum Reprod 200I, 7:483-488

17. VanHummelen P, Manchester D, Lowe X, Wyrobek AJ: Meiotic segregation, recombination, and gamete aneuploidy assessed in a $\mathbf{t}(1 ; 10)(p 22.1 ; q 22.3)$ reciprocal translocation carrier by three- and fourprobe multicolor FISH in sperm. Am J Hum Genet 1997, 61:651-659.

18. Blanco J, Egozcue J, Clusellas N, Vidal F: FISH on sperm heads allows the analysis of chromosome segregation and interchromosomal effects in carriers of structural rearrangements: results in a translocation carrier, $t(5 ; 8)(q 33 ; q 13)$. Cytogenet Cell Genet 1998, 83:275-280.

19. Cifuentes P, Navarro J, Blanco J, Vidal F, Mýnguez L, Egozcue J, Benet $\mathrm{J}$ : Cytogenetic analysis of sperm chromosomes and sperm nuclei in a male heterozygous for a reciprocal translocation $\mathbf{t}(5 ; 7)(\mathbf{q} 21 ; \mathbf{q} 32)$ by in situ hybridisation. Eur J Hum Genet 1999, 7:231-238.

20. Estop AM, Cieply KM, Munne S, Feingold E: Multicolor fluorescence in situ hybridization analysis of the spermatozoa of a male heterozygous for a reciprocal translocation t(I I;22)(q23;q I I). Human Genetics 1999, 104:4 I2-4I 7.

21. Prado-Manuel de Villena F, Sapienza C: Transmission ratio distortion in offpring of heterozygous female carriers of Robertsonian translocations. Hum Genet 200I, 108:31-36.

22. Pellestor $F$, Sele B, Jalbert $H$ : Chromosome analysis of spermatozoa from a male heterozygous for a 13;14 Robertsonian translocation. Hum Genet 1987, 76: I 16-120.

23. Martin RH: Cytogenetic analysis of sperm from a male heterozygous for a 13;14 Robertsonian translocation. Hum Genet 1988, 80:357-361.

24. Roux C, Tripogney F, Morel C, Joanne F, Fellmann MC, Bresson JL: Segregation of chromosome in sperm of Robertsonian translocation carriers. Cytogenet Genome Res 2005, I I I:291-296.

25. Lejeune J: Autosomal disorders. Pediatrics 1963, 32:326-337.

26. Miharu N, Best RG, Young SR: Numerical chromosome abnormalites in spermatozoa of fertile and infertile men detected by fluorescence in situ hybridation. Hum Genet 1994, 93:502-506.

27. Moosani N, Cox DM, Pattinson HA, Rademaker AW, Carter MD, Martin RH: Chromosomal analysis of sperm from men with idiopathic infertility using sperm karyotyping and fluorescence in situ hybridization. Fertil Steril 1995, 64:8I I-8I7.

28. Pellestor F, Imbert I, Andréo B, Lefort G: Study of the occurence of interchromosomal effect in spermatozoa of chromosomal rearrangement carriers by fluorescence in-situ hybridization primed in-situ labelling techniques. Hum Reprod 200I, 16:1155-1164

29. Anton E, Blanco J, Egozcue J, Vidal F: Sperm FISH studies in seven male carriers of Robertsonian translocation

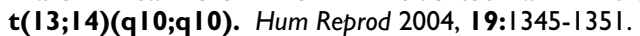

30. Lejeune J, Maunoury C, Prieur M, Akker J Van den: A jumping translocation (5p;15q), (8q; 15q), and (12q;15q). Ann Genet 1979, 22:210-213.

31. Iwarsson E, Sahlén S, Nordgren: Jumping translocation in a phenotypically normal male: A study of mosaicism in spermatozoa, lymphocytes, and fibroblasts. A Am J Med Genet A 2009, I49A(8): I 706-II.

32. Eaker S, Pyle A, Cobb J, Handel MA: Evidence for meiotic spindle checkpoint from analysis of spermatocytes from Robertsonian-chromosome heterozygous mice. J Cell Sci 200I, I | 4:2953-2965

33. Vegetti W, Van Assche E, Frias A, Verheyen G, Bianchi MM, Bonduelle $M$, Liebaers I, Van Steirteghem A: Correlation between semen parameters and sperm aneuploidy rates investigated by fluorescence in-situ hybridization in infertile men. Hum Reprod 2000, I 5(2):35I-65.

34. Machev N, Gosset P, Warter S, Treger M, Schillinger M, Viville S: Fluorescence in situ hybridization sperm analysis of six translocation carriers provides evidence of an interchromosomal effect. Fertil Steril 2005, 84(2):365-73.

35. Luciani JM, Guichaoua MR, Mattei A, Morazzani MR: Pachytene analysis of a man with a $13 q ; \mid \mathbf{~} q$ translocation and infertility. Behavior of the trivalent and nonrandom association with the sex vesicle. Cytogenet Cell Genet 1984, 38: I4-22.

36. Grao P, Coll MD, Ponsa M, Egozcue J: Trivalent behavior during prophase I in male mice heterozygous for three Robertsonian translocations: an electron-microscopic study. Cytogenet Cell Genet 1989, 52:105-I I0.

37. Sciurano R, Rahn M, Rey-Valzacchi G, Solari AJ: The asynaptic chromatin in spermatocytes of translocation carriers contains the histone variant $\gamma-\mathrm{H} 2 \mathrm{AX}$ and associates with the $X Y$ body. Human Reprod 2007, 22: I42-I50.

38. Martin RH: Mechanisms of nondisjunction in human spermatogenesis. Cytogenet Genome Res 2005, I I I:245-249.

39. Downie SE, Flaherty SP, Matthews CD: Detection of chromosomes and estimation of aneuploidy in human spermatozoa using fluorescence in-situ hybridization. Mol Hum Reprod 1997, 3:585-598.

40. Anahory T, Hamamah S, Andréo B, Hédon B, Claustres M, Sarda P, Pellestor F: Sperm segregation analysis of a $(13 ; 22)$ Robertsonian translocation carrier by FISH: a comparison of locusspecific probe and whole chromosome painting. Hum Reprod 2005, 20(7): 1850-4.

41. SAS Institute Inc: SAS/STAM ${ }^{\mathrm{TM}}$. SAS user's guide for windows environment. 8.02 ed. Cary, SAS Institute Inc; 200I.

\section{Publish with Bio Med Central and every scientist can read your work free of charge}

"BioMed Central will be the most significant development for disseminating the results of biomedical research in our lifetime. "

Sir Paul Nurse, Cancer Research UK

Your research papers will be:

- available free of charge to the entire biomedical community

- peer reviewed and published immediately upon acceptance

- cited in PubMed and archived on PubMed Central

- yours - you keep the copyright
BioMedcentral 